\title{
Motivasi Keterwakilan Perempuan dalam Politik pada Pemilu Legislatif di Kabupaten Tanah Laut
}

\author{
Mariatul Kiptiah \\ Jurusan Teknologi Industri Pertanian, Politeknik Negeri Tanah Laut, \\ Email: mariatul@politala.ac.id
}

\begin{abstract}
Abstrak
Keterwakilan perempuan dalam pemilu legislatif merupakan gambaran proses demokrasi dimana partai-partai politik memberikan otoritas bagi perempuan untuk membuat kebijakan yang berorientasi dalam pemenuhan hak-hak perempuan khususnya kesetaraan gender. Gambaran demokrasi yang dilakukan melalui motivasi atau keinginan bagi para calon legislatif perempuan sebagai pemenuhan hak keterwakilan perempuan di politik pada saat nanti terpilih sebagai wakil rakyat dapat membawa aspirasi masyarakat dan membawa arah kebijakan pembangunan bagi daerah. Penelitian ini menggunakan analisis deskripsi kualitatif (cualitative research approach) dengan cara pengumpulan data survei, wawancara mendalam, pembagian kuesioner terhadap responden yang diteliti sebanyak 6 anggota legislative incumbent dan 10 orang terdaftar sebagai DCT oleh KPU. Analisis data yang digunakan dalam penelitian ini mencakup pendapat para responden dalam menentukan keadaan motivasi pada caleg perempuan dengan menggunakan Statistical Package For Social Science (SPSS) versi 16. Adapun hasil penelitian yang dilakukan bahwa persentase keterwakilan perempuan dalam pemilu yang dilaksanakan dalam waktu 5 tahun sekali mengalami peningkatan dari pemilu 1992-1999 sebesar 9.2\%, pemilu 1999-2004 sebesar 11, $8 \%$, tahun 2004-2009 sebesar $18,2 \%$ dan $2009-2014$ sebesar $17,3 \%$. Ini menggambarkan bahwa refresentasi partisipasi keterwakilan caleg perempuan mengalami kenaikan dalam pemilu. Jumlah partisipasi pemilih perempuan dikabupaten Tanah Laut serta motivasi Caleg perempuan dalam pemenuhan kouta 30 persen dalam kategori tinggi dengan persentase $100 \%$. Artinya caleg perempuan di Tanah Laut sudah memiliki strategi untuk mendapatkan perolehan suara dalam persaingan politik sesuai dengan daerah pemilihan masing-masing.
\end{abstract}

Kata Kunci: Motivasi,Keterwakilan Perempuan dan Pemilu Legislatif

Abstract

Women's representation in legislative elections is an illustration of the democratic process in which political parties give authority for women to make policies that are oriented towards fulfilling women's rights, especially gender equality. The description of democracy carried out through motivation or desire for women legislative candidates as fulfilling the right to represent women in politics when they are elected as representatives of the people can bring the aspirations of the people and bring the direction of development policies for the region. This research uses qualitative description analysis (cualitative research approach) by means of survey data collection, in-depth interviews, questionnaire distribution to the surveyed respondents as many as 6 legislative members and 10 people registered as DCT by the KPU. Analysis of the data used to see the research of the opinions of respondents in determining the state of motivation in female candidates can be used by Statistical Package For Social Science (SPSS) version 16. The results of research conducted that the percentage of women's representation in elections held within 5 years once experienced an increase from the 1992-1999 elections by $9.2 \%$, the 1999-2004 elections amounted to $11,8 \%, 2004-2009$ by $18.2 \%$ and $2009-2014$ at $17.3 \%$. This illustrates that the representation of representation participation of female candidates has increased in the election. The number of female voter 
participation in Tanah Laut Regency and the motivation of female candidates in fulfilling the 30 percent quota in the high category with a percentage of 100 percent. This means that female candidates in Tanah Laut already have a strategy to get votes in political competition in accordance with their respective electoral districts.

Keyword: Motivation, candidate legislative women and legislative elections

\section{PENDAHULUAN}

Pemilu merupakan sebuah proses demokrasi suatu bangsa dalam menentukan pilihan terhadap perwakilan rakyat yang dipilih. Demokrasi memberikan gambaran mengenai kedewasaan setiap partai politik untuk ikut berpartisipasi dalam proses pemilu. Salah satu cara yang dilakukan oleh partai-partai politik yaitu melalui rekrutmen calon legislatif.

Rekrutmen politik yang dilakukan oleh partai-partai politik memberikan peluang dan harapan besar terhadap calon tetap legislatif khususnya keterwakilan perempuan untuk ikut berpartisipasi serta menciptakan sistem seleksi internal yang terbuka, responsif serta berintegritas dalam proses pemilu.

Amanat Undang-Undang Nomor 7 Tahun 2017 pasal 173 ayat 2 mengenai Pemilu menyebutkan bahwa keterwakilan perempuan 30 persen hanya berlaku pada tingkat pusat saja dan tidak pada tingkat kabupaten/kota. Undang-Undang ini dinilai belum memberikan keuntungan bagi perempuan untuk ikut berpartisipasi pada pemilu, dikarenakan masih normatifnya partai politik dan ketidakseriusan dalam mengusahakan terhadap keterwakilan kouta 30 persen perempuan dari setiap daerah pemilihan.

Keterwakilan perempuan dalam pemilu legislatif ini menjadi perhatian penting bagi partai-partai politik lantaran kehadiran perempuan terlibat aktif dalam politik mampu memberikan otoritas bagi perempuan untuk membuat kebijakan yang berorientasi pada perempuan dalam pencapaian hak-hak perempuan khususnya kesetaraan gender. Selain itu, rendahnya keterwakilan perempuan ini didasarkan masih mengakarnya paradigma patriarki di sebagian besar masyarakat yang cenderung menempatkan posisi perempuan dibawah kekuasaan laki-laki.

Sesuai dengan PKPU tahun 2018 telah memberikan kebijakan afirmatif bagi perempuan yaitu melalui pemenuhan kouta 30 persen dalam pemilu serta menjadikan perempuan berada pada semua unsur pelaksaaan proses demokrasi yang dibangun diatas praktek dan prinsip tata pemerintahan yang baik dan berkelanjutan.

Gambaran demokrasi yang berkelanjutan ini tentunya harus dilakukan melalui motivasi atau keinginan bagi para calon legislatif perempuan sebagai pemenuhan hak keterwakilan perempuan di politik pada saat nanti terpilih sebagai wakil rakyat untuk dapat membawa aspirasi masyarakat serta mampu membuat arah kebijakan yang berpihak terhadap orang banyak dan dapat bekerja dengan penuh amanah. (Winardi, 2004).

Adanya motivasi dan keinginan dari calon legislatif perempuan ini yang melatar belakangi terhadap pemenuhan kouta 30 persen perempuan dalam pemilu terpenuhi serta mampu menjadikan keterwakilan perempuan di partai-partai politik bukan hanyalah sebagai pelengkap dalam mengisi ruang kosong saja serta untuk memenuhi nomor urut yang belum terisi, akan tetapi harus memiliki peran strategis dalam memperjuangkan hak-hak rakyat khususnya pada isu perempuan dan anak. Selain itu, perlu dilakukan pengkaderan sejak dini oleh partai-partai politik agar pemenuhan jumlah kader perempuan mampu bersaing dalam kancah perpolitikan di parlemen.

\section{METODE PENELITIAN}

A. Waktu dan tempat penelitian

Penelitian ini dilakukan dalam kurun waktu saat pengumuman pengusulan daftar calon sementara legislatif perempuan oleh partai politik ke KPU sampai sesudah pengumuman daftar calon tetap legislatif yang disahkan oleh KPU peserta partai politik. Penelitian ini mengambil tempat di daerah kabupaten Tanah Laut, melihat motivasi dan partisipasi calon legislatif perempuan yang sangat mendominasi pada keterwakilan perempuan di 20 partai politik peserta Pemilu tahun 2019. 
B. Pengolahan dan pengumpulan data

Pengumpulan dan pengolahan data dilakukan dengan cara analisis deskripsi kualitatif (cualitative research approach) yaitu melihat data proses dari kebijakan yang diberlakukan. Adapun pengumpulan data dengan cara survei, wawancara mendalam, pembagian kuesioner terhadap responden yang diteliti menggunakan metode Purposive sampling yaitu teknik pengambilan sampel sumber data dengan pertimbangan tertentu. Alasan menggunakan teknik Purposive Sampling adalah karena tidak semua sampel memiliki kriteria yang sesuai dengan fenomena yang diteliti. Oleh karena itu, penulis memilih teknik Purposive Sampling yang menetapkan pertimbangan-pertimbangan atau kriteriakriteria tertentu yang harus dipenuhi oleh sampel-sampel yang digunakan dalam sebuah penelitian. (Sugiyono, 2009)

C. Metode Analisis Data

Analisis data yang digunakan untuk melihat penelitian dari pendapat para responden dalam menentukan keadaan motivasi pada caleg perempuan dapat digunakan dengan cara Statistical Package For Social Science (SPSS) versi 16.

D. Subjek penelitian

Subjek yang diminta data berupa wwancara dan kuesioner adalah anggota DPRD perempuan yang masih aktif sebagai legislator periode 2014-2019 sebanyak 6 orang dan ditambah dengan data para calon anggota legislatif yang terdaftar sebagai DCT oleh KPU dari lintas partai sebanyak 10 orang yang terdiri dari PDI Perjuangan sebanyak 2 orang, Partai GERINDRA sebanyak 2 orang, Partai Golongan karya sebanyak 2 orang, Partai Amanat Nasional sebanyak 2 orang dan Partai Keadilan Sejahtera sebanyak 2 orang.

\section{HASIL DAN PEMBAHASAN}

Demokrasi merupakan suatu upaya dalam menjamin hak politik sebagai warga negara Indonesia khususnya pemilih perempuan. Pada pertemuan konferensi Perserikatan bangsa-bangsa (PBB) di Beijing, isu perempuan menjadi pembicaraan yang diangkat sebagai wujud keterwakilan perempuan dalam politik. Permasalahan yang sangat krusial diangkat mengenai kesetaraan gender, dikarenakan perempuan harus ikut andil dalam pengambilan kebijakan sebuah politik supaya dapat memperkokoh permasalahan yang dihadapi oleh masyarakat, seperti KDRT, Kenakalan remaja serta masalah kebangsaan yang menyangkut hak perempuan.

Menurut pakar politik Mulyono (2010) menyampaikan saat Seminar RUU pemilu bahwa refresentasi keterwakilan perempuan dalam politik setiap 5 tahun sekali mengalami peningkatan, yaitu: sejak pemilu 1992-1999 sebesar 9.2\%, pemilu 1999-2004 sebesar 11, 8\%, tahun 2004-2009 sebesar 18,2\% dan 20092014 sebesar 17,3\%. Hal ini juga didasarkan pada kandidat perempuan yang mencalonkan diri dan masuk dalam daftar pemilih mengalami kenaikan yang sangat signifikan dari 2009 sebesar 33,6\% dan 2014 menjadi $37 \%$.

Meskipun secara Undang-Undang belum mencapai afirmasi 30 persen keterwakilan perempuan, tentunya pada persipan pemilu di tahun 2019 ini sebagai upaya penguatan kapasitas calon legislatif perempuan untuk komitmen dan berjuang dalam memajukan perempuan di Indonesia.

Melihat gambaran partisipasi perempuan dalam pemilu 2019 ini, berdasarkan data yang didapat dari KPU kabupaten Tanah Laut bahwa jumlah daftar pemilih tetap hasil perbaikan (DPHTP-2) Pemilihan Umum tahun 2019 dapat dilihat pada Tabel 1:

TABEL 1

DATA DPHTP-2 TAHUN 2019

\begin{tabular}{|c|c|c|c|c|c|}
\hline \multirow{2}{*}{ No } & \multirow{2}{*}{ Nama Kecamatan } & \multirow{2}{*}{ Jumlah Desa } & \multirow{2}{*}{ Jumlah TPS } & \multicolumn{2}{|c|}{ Jumlah Pemilih } \\
\cline { 4 - 6 } & & & $\mathrm{L}$ & $\mathrm{P}$ \\
\hline 1 & Bajuin & 9 & 57 & 6,897 & 6,587 \\
\hline 2 & Bati-Bati & 14 & 130 & 15.765 & 15,282 \\
\hline
\end{tabular}




\begin{tabular}{|c|c|c|c|c|c|}
\hline \multirow{2}{*}{ No } & \multirow{2}{*}{ Nama Kecamatan } & \multirow{2}{*}{ Jumlah Desa } & \multirow{2}{*}{ Jumlah TPS } & \multicolumn{2}{|c|}{ Jumlah Pemilih } \\
\cline { 5 - 6 } & & & $\mathrm{L}$ & $\mathrm{P}$ \\
\hline 3 & Batu Ampar & 14 & 83 & 10,075 & 9,513 \\
\hline 4 & Bumi Makmur & 11 & 45 & 5,094 & 4,890 \\
\hline 5 & Jorong & 11 & 98 & 12,346 & 11,652 \\
\hline 6 & Kintap & 14 & 126 & 15,422 & 14,403 \\
\hline 7 & Kurau & 11 & 43 & 4,930 & 4,878 \\
\hline 8 & Panyipatan & 10 & 71 & 8,946 & 9,024 \\
\hline 9 & Pelaihari & 20 & 235 & 26,552 & 26,995 \\
\hline 10 & Takisung & 12 & 98 & 11,909 & 11,789 \\
\hline 11 & TambangUlang & 9 & 51 & 6,218 & 6,051 \\
\hline & Total & $\mathbf{1 3 5}$ & $\mathbf{1 0 3 7}$ & $\mathbf{1 2 4 , 1 0 9}$ & $\mathbf{1 2 1 , 0 6 4}$ \\
\hline
\end{tabular}

Sumber: KPU Kabupaten Tanah Laut

Data diatas menunjukkan bahwa angka partisipasi pemilih di Kabupaten Tanah Laut bagi pemilih perempuan dikatakan sudah partisipatif dalam menentukan kebijakan politik secara langsung, ini digambarkan dari jumlah pemilih perempuan serta daftar calon tetap legislatif dari 20 peserta partai politik yang memenuhi kouta 30 persen perempuan yang sangat termotivasi untuk mengikuti proses demokrasi yang akan berlangsung pada tanggal 17April 2019. Menurut pendapat Koeswara (2009), untuk menentukan seseorang terlibat aktif dalam politik seperti menjadi anggota suatu partai politik dilihat dari keterlibatannya sebagai anggota legislatif dengan cara ikut berpartisipasi dalam Pemilu.

Partai politik memberikan fungsi dan tujuan yang mendasar dari rekrutmen keterlibatan perempuan sesuai dengan Undang-Undang Nomor 7 Tahun 2017 dalam pemenuhan kouta 30 persen perempuan sebagai sarana sosialisasi politik dalam memperoleh pandangan dan mencerminkan nilai-nilai di masyarakat. Penjelasan mengenai partai politik ini menurut Thoha (2004) sebagai organisasi yang memiliki hubungan kekuasaan dengan cara pemilihan demokratis melalui mekanisme perwakilan atau parlemen.

Meningkatkan peran pada partai politik ini dilihat dari motivasi kouta 30 persen perempuan dengan hasil yang diperoleh dari jumlah responden terdiri dari 6 orang incumbent periode 2014-2019 dan 10 orang Caleg dari partai politik yang berbeda menunjukkan bahwa:

TABEL 2 .

DESKRIPSI HASIL DATA PENELITIAN

\begin{tabular}{|c|c|c|c|c|c|c|c|c|}
\hline \multirow{2}{*}{ Variabel } & \multicolumn{4}{|c|}{ Data Hipotetik } & \multicolumn{4}{c|}{ Data Empirik } \\
\cline { 2 - 9 } & Xmaks & Xmin & Mean & SD & Xmaks & XMin & Mean & SD \\
\hline $\begin{array}{c}\text { Partai } \\
\text { Politik }\end{array}$ & 96 & 24 & 60 & 12 & 94 & 60 & 76,26 & 7,46 \\
\hline
\end{tabular}

Data tabel ini menunjukkan bahwa jumlah analisis deskriptif pada jawaban motivasi adalah minimal 24 dan maksimal 96 sedangkan nilai rerata sebesar 60 dengan nilai 76,26 dan simpangan baku sebesar 12 dengan nilai 7,26. Dari angka yang disajikan memberikan gambaran bahwa partisipasi perempuan dalam politik dan keikutsertaan pada Pemilu 2019 memberikan angka motivasi yang tinggi dengan persentase $100 \%$.

Motivasi yang tinggi dari partisipasi perempuan dalam politik ini ditentukan juga dengan beberapa alasan, sebagaiman pendapat McClelland (1987) dalam tiga kriteria, yaitu: need for power, berarti memiliki karakteristik yang dominan dan cenderung mengendalikan situasi pada internal partai serta memiliki ambisi yang kuat untuk membuat partai mencapai visi dan misinya. Need for affiliation memiliki kecenderungan bagi calon legislatif dalam menentukan partai yang memiliki program- 
program pro-rakyat atau adanya hubungan emosional dengan para tokoh atau pimpinan partai. Sedangkan need for achievement berarti memiliki kecenderungan memilih partai yang dapat membuat individu tersebut lebih menonjol dari anggota satu partai.

Beberapa kriteria diatas, tentunya harus didukung dengan strategi yang harus disiapkan oleh caleg perempuan dalam persiapan mengikuti pemilu 2019 ini dengan cara:

1. Visi-misi yang diusung oleh para celeg perempuan diutamakan pada isu perempuan dan anak tujuannya untuk mendapatkan simpati khususnya kalangan pemilih persentase perempuan dan kaum ibu, misalnya tentang kesehatan, pendidikan, tenaga kerja, UMKM.

2. Melihat persaingan yang ketat, para caleg perempuan harus perlu bekerja keras untuk berkompetisi secara sehat dengan imcumbent, pendatang baru internal partai serta caleg laki-laki. Salah satu cara kerja yang harus dilakukan yaitu kampanye inovatif, kreatif dan edukatif.

3. Caleg perempuan harus melakukan pemetaan politik yang tepat, yaitu melalui survei maupun riset yang terpercaya untuk mengetahui demografi pemilih di wilayah pemilihan dapil yang bersangkutan.

4. Caleg perempuan yang berada pada nomor urut dibawah jangan berputus asa, melainkan harus mampu mengambil simpati kepada pemilih melalui kampanye, sosialisasi door to door serta melakukan silaturahmi sesering mungkin ke masyarakat pemilih.

Berdasarkan uraian diatas, maka penulis mengambil suatu kesimpulan bahwa jumlah persentase calon legislatif perempuan yang mengikuti pesta demokrasi pada Pemilu 2019 semakin meningkat dengan memiliki motivasi yang tinggi dan termasuk kategori Need for affiliation dengan tujuan untuk meraih jumlah suara yang lebih besar sehingga kiprah perempuan dalam pemenuhan hak politiknya dapat menjadi perbaikan dalam kebijakan terhadap hak-hak perempuan serta dapat mengisi pembangunan di Tanah Laut menjadi lebih baik.

\section{KESIMPULAN DAN SARAN}

Berdasarkan hasil penelitain yang dilakukan oleh peneliti, maka dapat disimpulkan bahwa:

1. Persentase keterwakilan perempuan dalam pemilu yang dilaksanakan dalam waktu 5 tahun sekali mengalami peningkatan dari pemilu 1992-1999 sebesar 9.2\%, pemilu 1999-2004 sebesar 11, 8\%, tahun 2004-2009 sebesar 18,2\% dan 2009-2014 sebesar 17,3\%. Ini menggambarkan bahwa refresentasi partisipasi keterwakilan caleg perempuan mengalami kenaikan dalam pemilu.

2. Jumlah partisipasi pemilih perempuan dikabupaten Tanah Laut serta motivasi Caleg perempuan dalam pemenuhan kouta 30 persen sebagai peserta pemilu dalam kategori tinggi dengan persentase $100 \%$. Artinya caleg perempuan di Tanah Laut Need for affiliation dalam menentukan arah kebijakan politik bagi perempuan serta memiliki strategi untuk mendapatkan perolehan suara pada daerah pemilihan masing-masing.

Setelah melakukan penelitian ini, maka secara substansial, peneliti memberikan saran sebagai masukan perbaikan untuk pemilu akan datang:

1. Dalam melakukan rekrutmen terhadap caleg perempuan harus diberikan keleluasaan tanpa dibatasi dengan jumlah calon perempuan yang ikut mendaftar pada partai politik peserta pemilu.

2. Caleg perempuan harus memiliki komitmen yang kuat untuk siap bersaing dalam proses pemilu agar dapat memotivasi perempuan yang lain melalui keterampilan dan keahlian serta dapat berdampingan dengan caleg laki-laki untuk melaksanakan pembangunan daerah menjadi lebih baik.

\section{DAFTAR PUSTAKA}

Basuki, A. T. Bahan Ajar Ekonometrika, Regresi Berganda dan Uji Asumsi Klasik Dengan SPSS. Yogyakarta: Universitas Muhammadiyah.

Koeswara, H. (2009). Partisipasi Politik kader Perempuan Partai Politik (Studi kasus tentang kendala partisipasi politik kader perempuan dalam kegiatan parpol pada pelaksanaaan pilkada di Provinsi Jambi). Jakarta. 


\section{$\mathbf{T}$}

Jurnal Humaniora Teknologi

p-ISSN: 2443-1842

Volume 5, Nomor 1, Mei 2019

Mc.Clelland. (1987). Human Motivation. Australia: Press Syndicate The University of Cambridge.

Sugiyono. (2009). Metode Penelitian Kuantitatif kualitatif DAN R\&D Cetakan ke-14. Bandung: Alfabeta.

Winardi. (2004). Motivasi dan Pemotivasian. Jakarta: Grasindo.

Undang-Undang Nomor 7 Tahun 2017 tentang Pemilu Keterwakilan Perempuan

PKPU tahun 2018 tentang Pemenuhan Kouta 30 Persen Perempuan

Data KPU kabupaten Tanah Laut Tahun 2019 